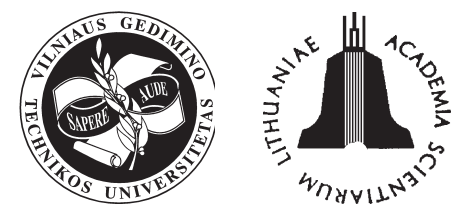

ISSN 1648-4142 TRANSPORT

http:/www.vtu.lt/english/editions

\title{
METHODOLOGICAL ASPECTS OF A QUESTIONNAIRE RESEARCHING TRANSPORTATION LINKS
}

\author{
Michail Litvinenko', Ramūnas Palšaitis² \\ Dept of Transport Management, Vilnius Gediminas Technical University, \\ Plytinès g. 27, LT-10105 Vilnius-16, Lithuania. Tel.: 2744776 \\ ${ }^{1}$ E-mail:michaill@mail.lt2E-mail:trvadyba@ti.vtu.lt
}

Received: 2004-11-14; accepted: 2005-01-25

\begin{abstract}
Changes of foreign trade conditions also bring changes of the main transport routes and directions. Lithuanian transport companies must perfect their ability to adapt in changing environment, to predict and reorient to the possible changes in the flow of goods, to observe changes and tendencies, in short to build a new foundation and appliance of transportation technologies. To aid this a questionnaire researching transport must be made. This article covers the analysis of the planning and conducting of the research and the data processing methodology used to determine the main directions of the flow of goods of Lithuanian transport companies as well as the criteria concerning competitiveness among the companies.
\end{abstract}

Keywords: transportation; research; loads; flows.

\section{Introduction}

In recent years a gross national product created by the Lithuanian transport sector is increasing and in 2003 it came to $9 \%$ of total GNP, though this result is achieved only by $5 \%$ of the whole working population. Thus, it can be affirmed that the transport sector plays an important role in the economic structure of the country determining its development and the progress of the whole society.

The centralization of foreign trade was dissolved 14 years ago allowing economic subjects to trade freely with foreign partners. Such reorientation of business has changed the geographic structure of Lithuanian business links and has had a positive impact on the development of the economy and structural changes of the whole country [1].

Development of foreign trade is an important objective of the Lithuanian government. This is being put into practise by liberalizing international trade and demanding that promotional programmes of export have an appropriate level of cooperation since these relations are grounded not only on mutual benefit, but also on the principles of good neighbourly values. Development of regional cooperation is gaining more and more importance constituting the right legal, financial and informative environment for the movement of goods and capital.

Transport (its infrastructure, technological pro- cess-ses and the means of transportation themselves) is the main means which provides a possibility for free movement of goods, adding value to them, i.e. ensuring the usefulness of time and place [2].

\section{Objective of the research}

The objective of the research is to investigate the tendencies of the territorial distribution of international trade routes and the influence of transport on the tendencies of the development of international trade.

The research covered both Lithuanian and foreign transportation companies. This choice (regarding completing the survey outside Lithuania) was determined by the fact that the aspiration was to identify the reasons for the choice of the route covering or not the Lithuanian territory as well as to define possible alternatives in terms of choosing the route.

To ensure high reliability of the data the research was conducted three times surveying the same respondents.

\section{Identification of the potential main problems as regards gathering information}

Whilst carrying out the survey, the main problem was to gather initial information since this pro- 
cess requires a great deal of labour. Problems regarding gathering of reliable initial information are also faced when trying to define the goals of the reorganization and the development of the system of transportation service. While planning the research, questions arise in connection with the methodology of gathering the information, determining the extent of the research and the preliminary correction of possible mistakes arising in the course of processing and modelling of the data of the research.

In order to make the research cheaper and simpler it is possible to make use of report-statistic data of the appropriate departments. However, it is a problem as some information is confidential and not all the data gathered in departments are available to the general public (for example statistical data from the Statistics department). Furthermore, report-statistic data are not sufficient when analysing the configuration of transport channels, grounding territorial distribution of transport terminals and logistics centres, the selection of the structure of the transport park, its size and the like.

\section{Methodology of the research organization}

The problems indicated above can be solved by using natural data of transport research, which can be obtained making observations at the fixed points of the transport infrastructure and surveying the staff of transportation companies (heads of the companies, transportation managers and forwarding agents), as well as making a selective survey among the drivers of cargo-carrying means of transport in specific places of the transportation net.

It is a fact that it is the most appropriate to conduct transport research on those highways where traffic intensity amounts to 10.000 vehicles per 24 hours and above [3]. Whilst conducting the research, the main point to be taken into consideration is that even if the research is ideally organized there is no possibility to stop all the cargo-carrying cars passing-by and survey their drivers.

It is also advisable that several characteristics of the transport flow which increase the extent of the general set in several or tens of times should be determined [4]. For this reason in order to obtain the necessary information it is advisable that selective transport research should be made determining in advance the extent of the research and summing up the reliability of the data and possible mistakes.

During the research the emphasis was put on the determination of territorial distribution of routes of various types of cargo-carrying means of transport (ex.: tows with tilt semi-trailers, tows with isothermal semi-trailers and the like).
In the beginning of the research the structure of the loads and other characteristics were accepted and that in the net of highways $N$-cargo-carrying means of transport are moving. Let us admit that $p$ is a part of cargo-carrying vehicles (tows with tilt semi-trailers) and $q$ is the rest part of cargo-carrying vehicles. Previously it was mentioned that there is no real possibility to survey all the drivers of cargo-carrying vehicles and to determine precisely the meaning of $p$ and $q$ due to the extent of general set $N$.

Let us assume that we surveyed $n$ drivers and established that $p_{0}=\frac{m}{n}$ is a part of cars with $A$ characteristic in the flow of transport. Since $p_{0}$ is a realization of a certain chance quantity, (range) of $p$ reliability level can be determined only by using a theory of probability.

Summing up that the researchers working in the field of investigations of territorial distribution of transport bonds are most often satisfied when the results are reliable in 90-95\%, we accept this condition, therefore $P$ value with 0,9 reliability is defined in the following way:

$$
\begin{aligned}
& p_{0}-1,64 \sqrt{\frac{(N-n) p \cdot q}{(N-1) n}} \leq p \leq p_{0}+ \\
& 1,64 \sqrt{\frac{(N-n) p \cdot q}{(N-1) n}} .
\end{aligned}
$$

Since the values of $p$ and $q=1-p$ are not known exactly, the conclusions will fit if in formula (1) maximum values are inserted.

It is known that $\max p \cdot q=0,25$. Thus $p+q=1$.

$$
\begin{aligned}
& p_{0}-1,64 \sqrt{\frac{0,25(N-n)}{(N-1) n}} \leq p \leq p_{0}+ \\
& 1,64 \sqrt{\frac{0,25(N-n)}{(N-1) n}},
\end{aligned}
$$

$p_{0}-0,82 \sqrt{\frac{N-n}{(N-1) n}} \leq p \leq p_{0}+0,82 \sqrt{\frac{N-n}{(N-1) n}}$.

With the chance of 0,95 we will have accordingly:

$p_{0}-0,98 \sqrt{\frac{N-n}{(N-1) n}} \leq p \leq p_{0}+0,98 \sqrt{\frac{N-n}{(N-1) n}}$.

Let us assume that

$$
\varepsilon=0,82 \sqrt{\frac{N-n}{(N-1) n}} .
$$


$p$ deviation from $p_{0}$ is acceptable for us.

Then with the probability of 0,9 we can define the size of selective research in the following way:

$$
n=\frac{N}{1-1,4872 \varepsilon^{2}(N-1)} .
$$

By equation number 6 we can determine the number of the drivers to survey wishing to obtain the value $p$ with an error of calculation $\varepsilon$ and reliability level of $90 \%$.

Analogically making use of equation (4) we can define that:

$$
\begin{aligned}
& \varepsilon=0,98 \sqrt{\frac{N-n}{(N-1) n}}, \\
& n=\frac{N}{1+1,0412 \varepsilon^{2}(N-1)} .
\end{aligned}
$$

Using equation (8) we can define the number of the drivers to survey wishing to gain the value of $p$ with an error of calculation $\varepsilon$ and reliability level of $95 \%$.

In case the reliability level is chosen in advance, level $\varepsilon$ decreases when the extent of the survey increases.

Long term experience of the research into transport flows has shown that transport flows constantly change; therefore, it is necessary to repeat the research since onetime research can produce incorrect results.

In this case:

$$
\begin{aligned}
& n=\frac{t^{2} p(1-p)}{\varepsilon^{2}} K, \\
& K=1+k_{1}+k_{2}+k_{3}+k_{4},
\end{aligned}
$$

where $t$ - stands for the Student criterion; $K$ coefficient estimating inaccuracies and deviations due to making the data round $\left(k_{1}\right)$, unclear data $\left(k_{2}\right)$ incomplete record $\left(k_{2}\right)$, and inaccurate answers $\left(k_{4}\right)$.

Science advises not to limit only on certain characteristics of one factor, but also to invoke a multiple analysis of the problem. Therefore, it is advisable that the volume of the selective transport research according to all the factors should be determined using formula (10).

$$
n \geq \frac{t^{2}\left(\sum_{i}^{M} N_{k} \sigma_{k}^{2}\right)}{t^{2} \sum N_{k} \sigma_{k}+\left(\sum_{i}^{M} N_{k} \varepsilon_{r} \mu_{k}\right)^{2}} K
$$

where $\varepsilon_{r}$ is a relative mistake of separate factors and

$$
\varepsilon_{r}=\frac{t \sigma}{\mu \sqrt{n}},
$$

where $\mu_{k}-$ the arithmetic average of the factor of the whole general set.

When the necessary correctives and coefficients are inserted into these formulas, they can be applied not only for the research of routes of appropriate types of cargo-carrying vehicles, but also for the determination of business characteristics of transportation companies.

Whilst conducting the research we tried to define the markets where Lithuanian transportation companies operate and what companies buy services from them. Therefore, the respondents received a question helping to identify the main buyers of the services provided by Lithuanian transportation companies: "Who are the main customers using the services you provide?" In order to avoid possible variations of the same answer the respondents had to make a choice from some possible responses. The reply to this question consisted of two parts: the respondents had to mark appropriate providers of the services and to specify distribution in percentage (ex.: Lithuanian freight forwarding companies $-36 \%$, companies of Western Europe including EU countries - $45 \%$ and freight forwarding companies from Eastern Europe (Russia, Byelorussia) -19\%).

In order to identify which criteria are followed to choose the delivery route for goods the respondents had to answer the following question: "What criteria are followed in order to choose the route?". The criteria were estimated by importance (ex: safety factor - the most important and the days (weeks, months) during which the traffic of cargo-carrying vehicles was limited - the least important). This issue was more relevant surveying foreign companies because their replies will help to identify weak points in Lithuania as a transit country in specific fields of transportation service.

One of the objectives of the research was to establish clearly the main directions of the flow of goods and transit distribution. Since the services provided by Lithuanian transportation companies are used not only by Lithuanian, but also by foreign companies (transportation companies attend Lithuanian and foreign companies), therefore the question had several forms:

a) "If transportation services provided by your company are used by companies of Western Europe, what are the predominant directions of the flows of loads?"

b) "If transportation services provided by your company are used by companies of Eastern Europe, what are the predominant directions of the flows of loads?"

c) "If transportation services provided by your company are used by Lithuanian companies, what are 
the predominant directions of the flows of loads?"

In order to try to avoid essential inaccuracies and possible interpretations in the answers the respondents received some variants of possible responses. The answer to this question consisted of three parts: respondents had to mark the main direction of the flow of loads, to specify in percentage and enumerate the countries (ex.: Direction: Scandinavian countries - Eastern Europe, 12 \% Finland, Byelorussia; Direction: Lithuania - Western Europe, $86 \%$ Lithuania, Germany, France; Direction: Lithuania - Scandinavian countries, $2 \%$ Lithuania, Sweden).

One of the main questions was "What in your opinion induces foreign companies to choose the services provided by Lithuanian companies?". The essence of this question was to identify competitive advantages of Lithuanian transportation companies (the quality of services, the price of the service and the like). This was to be specified by transportation companies themselves. Before giving an answer to this question, the respondents had first of all to look critically at the activities their companies were engaged in and only after that to pick out what in their opinion would be the most attractive about their activities to foreign partners. The results of this research will help to evaluate market sectors attended by the main Lithuanian and foreign transportation companies, routes, distribution to individual countries, the change in the tendencies of the flows of loads, and etc.

After completing the research and applying the formulas (1)-(10), it has become possible to calculate the distribution of flows of individual types of cargo-carrying means of transport and the like.

\section{Analysis of the research data and the identifica- tion of the most frequent mistakes}

Drawing on many years of experience of transportation research it can be affirmed that in order to conduct the research it is essential to be well prepared in reference to the preparation of the questionnaire and appropriate processing of the results.

In the beginning of the research it is necessary, first of all, to select respondents (according to the criteria characteristic to an individual case), to select the place for the research and to calculate the extent of the research for an individual place.

After the necessary data is gathered, it must be processed. However, the analysis of the research data and execution procedures showed that in most cases certain difficulties arise, to be more precise - the same mistakes are encountered in almost every research, i.e. rounding the data up or down, unclear records, an incomplete record and inaccurate answers [4].

Rounding up or down of the data. Tendencies to round the data up or down are noticed in responses to the following questions: "What is the volume of the load", "Distance of transportation" and "Quantity of the loads carried". These mistakes are unavoidable since respondents are often not ready; therefore, the figures given are a rough estimate. A proportion of the mistakes made during data processing is avoided by virtue of comparative analysis; however, inaccurate answers are common in $5-10 \%$ of the questionnaires.

Unclear records. Unclear records occur when the survey is carried out on the road, the respondent's writing is hardly legible and abbreviations are used. Such mistakes are common in $0,5-10 \%$ of the questionnaires.

Incomplete record. This mistake is usually made when a questionnaire survey of freight shippers and consignees are organized by post or e-mail. Only 30 $40 \%$ of respondents fill in the questionnaire immediately on its receipt; therefore, it must be repeated again and again.

Inaccurate answers. Answers to the questions are subjective and are often inaccurate. The longer the period of the research, the more incorrect answers. The same applies to the distance of transport and defining territorial distribution of points where goods are loaded and unloaded. Incorrect answers constitute $5-10 \%$ of all the volume of the research.

By virtue of the research it was established that good preparation for transport investigations and blow-by-blow determination of the volume of research diminish the volume, duration and expense of the research to the minimum extent.

\section{Conclusions}

1. Market globalisation and increasing volumes of international trade are constantly raising demands for international business transportation services.

2. Endeavouring to identify road transport characteristics of transitional distribution, natural research into transportation flows must be executed.

3. It was established that whilst conducting the research into the flow of transport, problems naturally arise in connection with the choice of methodology regarding gathering of the information, determining of the extent of the research, preliminary correction of mistakes arising in the course of processing and modelling of the data of the research.

4. Summing up all possible variants and using the experience of Lithuanian as well as foreign experts, a questionnaire survey method was chosen for the research.

5. All the data gathered during the research enabled to identify the main directions of flows of 
transport bearing in mind seasons of transportation and volumes of the loads carried, as well as helped to determine the criteria for competitiveness among Lithuanian transportation companies.

\section{References}

1. Palšaitis, R. Transit Transport: the influence on the Intensity of the Traffic and on the Development of the Economics of the State. In: Transport: Technologies, Economics, Environment, Health (Transportas: technologijos, ekonomika, aplinka, sveikata). Vilnius: Technika, 2003, p. 153-204 (in Lithuanian).

2. Palšaitis, R.; Bazaras, D.; Labanauskas, G. The Comparative Analysis of Lithuanian and Latvian Transit Transport. Transport, Vol XIX, No 1, 2004 p. 9-15.

3. Jaržemskis, A. The Modelling of Factors Determining the Goods and Traffic Flows Movement in a Logistical System. Transport, Vol XVIII, No 1, 2003, p. 18-22.

4. Palšaitis, R. Planning of operational and strategic activities of transport in the system of the logistics. Habilitated Doctor's Thesis (Operatyvinis ir strateginis transporto veiklos planavimas logistikos sistemoje. Habilitacinis darbas). Vilnius: Technika, 1995. 165 p. 